\title{
False Recall Is Reduced by Damage to the Ventromedial Prefrontal Cortex: Implications for Understanding the Neural Correlates of Schematic Memory
}

\author{
David E. Warren, ${ }^{1}$ Samuel H. Jones, ${ }^{1,4}$ Melissa C. Duff, ${ }^{1,2}$ and Daniel Tranel ${ }^{1,3}$ \\ ${ }^{1}$ Department of Neurology, Carver College of Medicine and Departments of ${ }^{2}$ Communication Sciences and Disorders and ${ }^{3}$ Psychology, College of Liberal \\ Arts and Sciences, University of Iowa, Iowa City, Iowa 52242, and ${ }^{4}$ Department of Psychology, University of Notre Dame, South Bend, Indiana 46556
}

\begin{abstract}
Schematic memory, or contextual knowledge derived from experience (Bartlett, 1932), benefits memory function by enhancing retention and speeding learning of related information (Bransford and Johnson, 1972; Tse et al., 2007). However, schematic memory can also promote memory errors, producing false memories. One demonstration is the "false memory effect" of the Deese-Roediger-McDermott (DRM) paradigm (Roediger and McDermott, 1995): studying words that fit a common schema (e.g., cold, blizzard, winter) often produces memory for a nonstudied word (e.g., snow). We propose that frontal lobe regions that contribute to complex decision-making processes by weighting various alternatives, such as ventromedial prefrontal cortex (vmPFC), may also contribute to memory processes by weighting the influence of schematic knowledge. We investigated the role of human vmPFC in false memory by combining a neuropsychological approach with the DRM task. Patients with vmPFC lesions $(n=7)$ and healthy comparison participants $(n=14)$ studied word lists that excluded a common associate (the critical item). Recall and recognition tests revealed expected high levels of false recall and recognition of critical items by healthy participants. In contrast, vmPFC patients showed consistently reduced false recall, with significantly fewer intrusions of critical items. False recognition was also marginally reduced among vmPFC patients. Our findings suggest that vmPFC increases the influence of schematically congruent memories, a contribution that may be related to the role of the vmPFC in decision making. These novel neuropsychological results highlight a role for the vmPFC as part of a memory network including the medial temporal lobes and hippocampus (Andrews-Hanna et al., 2010).
\end{abstract}

\section{Introduction}

Contextual knowledge derived from previous experience is referred to as a schema (Bartlett, 1932; Alba and Hasher, 1983). Schemas exert a powerful organizing influence on memory that can produce improved recall (Bransford and Johnson, 1972), altered recall (Bartlett, 1932), or false recall (Roediger and McDermott, 1995). Here, false recall is plausible but inaccurate memory for events that allows related, nonspecific experience to proactively interfere with specific episodic memory. Therefore, accurate memory for a specific episode requires arbitration between competing schematic and episodic elements because a schema is likely to be partly consistent and partly inconsistent with a related episode. Although declarative memory for episodes and general knowledge is known to depend on the medial temporal lobe (MTL) and hippocampus (Scoville and Milner, 1957; Cohen and

\footnotetext{
Received Jan. 10, 2014; revised March 20, 2014; accepted April 23, 2014.

Author contributions: D.E.W., S.H.J., M.C.D., and D.T. designed research; D.E.W. and S.H.J. performed research; D.E.W. and S.H.J. analyzed data; D.E.W., S.H.J., M.C.D., and D.T. wrote the paper.

This work was supported by National Institute of Neurological Disorders and Stroke Grants P01 NS19632 (D.T.) and R01 DC011755 (M.C.D.) and National Institute of Mental Health Grant R01 MH062500 (D.E.W.). We thank D.

Kumaran for commenting on a previous version of this manuscript.

The authors declare no competing financial interests.

Correspondence should be addressed to David E. Warren, 2155-H RCP, 200 Hawkins Drive, lowa City, IA 52242. E-mail: david-e-warren@uiowa.edu.

DOI:10.1523/JNEUROSCI.0119-14.2014

Copyright $\odot 2014$ the authors $\quad 0270-6474 / 14 / 347677-06 \$ 15.00 / 0$
}

Squire, 1980), less is known about the brain regions supporting the integration of schematic memory.

A recent proposal (van Kesteren et al., 2012) suggested that medial prefrontal cortex (PFC) plays a critical role for new memories that overlap with existing knowledge, effectively weighting the influence of schematic memory. For example, increasing the weight of schematically related memories when recalling words fitting a "winter" schema would increase the probability of recalling the nonstudied word "snow" (as in the DRM paradigm). The ventromedial PFC (vmPFC) may serve as a neural substrate for this process because neuropsychological investigations have shown that vmPFC influences complex decision making by weighting different alternatives (Damasio, 1994; Bechara et al., 1997; Bechara and Damasio, 2005; Koenigs et al., 2007). Moreover, the vmPFC is anatomically (Ongür and Price, 2000; Saleem et al., 2008) and functionally (Ranganath et al., 2005; AndrewsHanna et al., 2010) connected with MTL regions supporting memory. Reflecting that connectivity, vmPFC (or a homologous region) is activated when schematic or contextual memory is exercised as shown in animal models (Euston and McNaughton, 2006; Tse et al., 2007, 2011) and neuroimaging studies (Kumaran et al., 2009; van Kesteren et al., 2010; 2013; Bonnici et al., 2012; Zeithamova et al., 2012a). In this context, it is notable that severe declarative memory impairments after vmPFC damage are uncommon (Janowsky et al., 1989; Stuss et al., 1994), although damage to vmPFC (sometimes extending to surrounding regions) 
Table 1. Demographic and neuropsychological information for the vmPFC patient group

\begin{tabular}{|c|c|c|c|c|c|c|c|c|c|c|c|c|c|c|c|c|c|c|}
\hline \multirow[b]{2}{*}{ ID } & \multirow[b]{2}{*}{ Sex } & \multirow[b]{2}{*}{ Hand } & \multirow[b]{2}{*}{ Age } & \multirow[b]{2}{*}{ Edu } & \multirow[b]{2}{*}{ Eti } & \multirow[b]{2}{*}{ Chr } & \multicolumn{4}{|l|}{ WAIS } & \multirow[b]{2}{*}{ COWA } & \multicolumn{2}{|l|}{ CF } & \multirow{2}{*}{$\frac{\text { AVLT }}{1 / 5 / \text { Delay }}$} & \multicolumn{4}{|l|}{ WMS } \\
\hline & & & & & & & VIQ & Sim & $\operatorname{lnf}$ & Voc & & Raw & Norm & & GMI & $\mathrm{Al}$ & $A D$ & ADR \\
\hline 0318 & M & 100 & 73 & 14 & Res. & 37 & 142 & 18 & 16 & 16 & 54 & 53 & 0.49 & $10 / 14 / 10$ & 109 & 118 & 114 & 125 \\
\hline 2025 & $\mathrm{~F}$ & 100 & 60 & 16 & Str. & 17 & 113 & 12 & 11 & 12 & 50 & 49 & -1.08 & $6 / 13 / 6$ & 114 & 105 & 99 & 130 \\
\hline 2391 & $\mathrm{~F}$ & 100 & 67 & 13 & Res. & 13 & 110 & 12 & 12 & 12 & 59 & 49 & 0.01 & $11 / 15 / 14$ & 132 & 120 & 124 & 120 \\
\hline 3350 & $M$ & 100 & 61 & 18 & Res. & 9 & 119 & 14 & 12 & 11 & 40 & 39 & -1.92 & $8 / 14 / 13$ & 108 & 117 & 114 & 100 \\
\hline 3383 & M & -100 & 63 & 12 & SAH & 6 & 95 & 11 & 7 & 9 & 47 & 43 & -0.76 & $4 / 12 / 8$ & $100^{a}$ & $98^{a}$ & $106^{a}$ & $105^{a}$ \\
\hline SD & & & 5.6 & 2.2 & & 9.7 & 14.5 & 2.5 & 2.6 & 2.4 & 10.2 & 6.0 & 1.00 & $2.4 / 1.1 / 2.8$ & 10.0 & 11.5 & 7.8 & 12.8 \\
\hline
\end{tabular}

The vmPFC patients were cognitively intact as a group, combining normal intellect with generally intact verbal functions and memory. Healthy comparisons were matched to patients 2:1 for sex, age, and education. ID, Patient identification number; $M$, male; F, female; Hand, handedness, from 100 (fully right-handed) to - 100 (fully left-handed); Edu, formal schooling in years; Eti, etiology, including resection (res.), stroke (str.), or subarachnoid hemorrhage (SAH); Chr, chronicity, years between brain injury and experimental task; WAIS, Weschler Adult Intelligence Scale, 3rd. edition; VIQ, WAIS-III verbal IQ (mean \pm SD, $100 \pm 15$ ); Sim, Inf, and Voc, WAIS-III similarities, information, and vocabulary subtests, age-corrected scaled scores (mean \pm SD, $10 \pm 3$ ); COWA, Controlled Oral Word Association task, age- and education-scaled scores (the normal range is 31-44, high normal is 45-52, and superior is $>53$ ); CF, category fluency task (tests generation of category exemplars for animals, tools, fruits, and vegetables); Raw, raw score; Norm, age-corrected Zscore; AVLT, Rey Auditory Verbal Learning Test, in which 1 indicates trial 1 performance, 5 indicates trial 5 performance, and Delay indicates 30 min delay performance (in all cases, score is raw recall of 15 possible); WMS, Wechsler Memory Scale-III (all WMS scores are age-corrected and have normative mean \pm SD of $100 \pm 15$ ); GMI, WMS general memory index; Al, WMS auditory immediate index; AD, WMS auditory delay index; ADR, WMS auditory delayed recognition index. Additional information on the neuropsychological tests has been described previously (Lezak et al., 2012).

${ }^{a}$ WMS scores were prorated for 3383.

${ }^{b}$ WAIS scores for 3534 are from WAIS-IV.

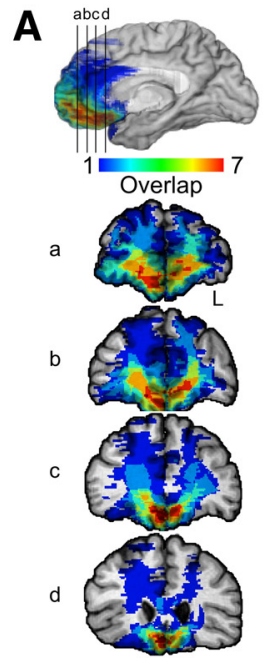

B

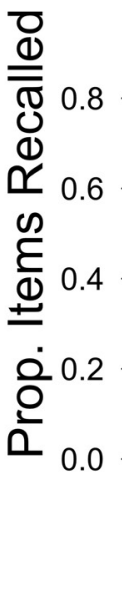

n.s.

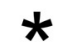

II

Group key:
C

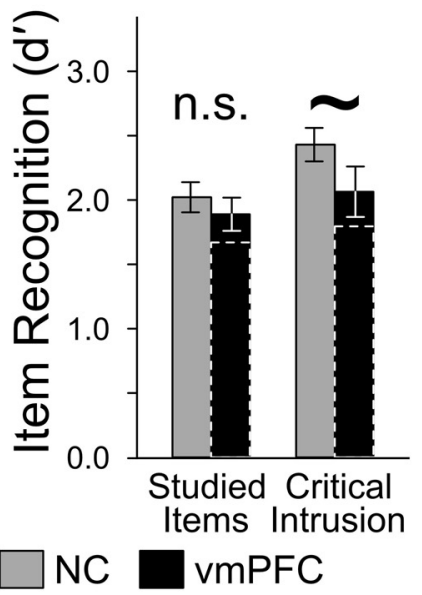

D

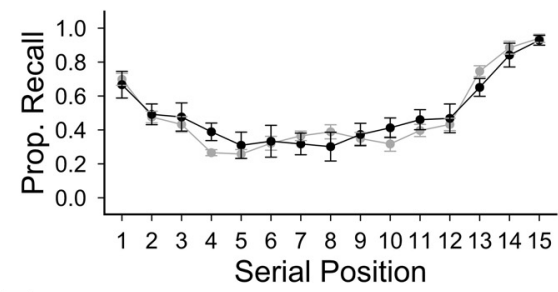

E

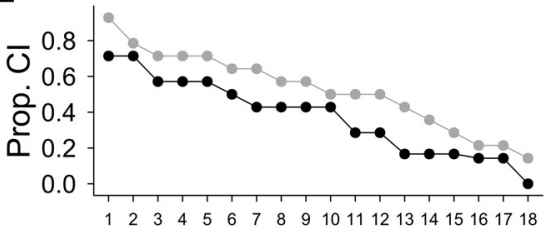

List Critical Intrusion Rank

Figure 1. Neuroanatomy of the vmPFC patients and performance of both groups on the DRM task. Healthy comparisons and vmPFC patients completed the DRM task, which provokes false recall and recognition through omission of a strong associate from a studied list of schematically related words. $\boldsymbol{A}$, Lesion overlap was concentrated in the vmPFC (hotter colors indicate more cases with overlapping lesions; see scale). Black lines in the medial view correspond to coronal slices (rostral to caudal; radiological convention, $\mathrm{L}$ marks left hemisphere). $\boldsymbol{B}$, Left, The comparison and vmPFC groups recalled a similar proportion of studied items, but (right) the vmPFC group had fewer critical intrusions than the comparison group (error bars indicate SEM; ${ }^{*} p<0.05 ;$ n.S., no statistical difference). C, Left, The comparison and vmPFC groups had similar recognition of studied items, but (right) the vmPF( group was somewhat less likely to incorrectly recognize critical items as studied (error bars indicate SEM; indicates marginal group difference). Solid bars indicate vmPFC group performance when patient 0318 was excluded; dashed bars reflect the inclusion of patient 0318 (Table 2). D, During recall, both groups showed typical primacy and recency effects. No significant between-group differences were observed (points indicate group means; error bars indicate SEM). $\boldsymbol{E}$, DRM lists provoked different rates of critical intrusion in the two groups. Comparisons produced more critical intrusions regardless of ranked list effectiveness (ordered from most to least effective for each group independently). Prop., Proportion; $\mathrm{Cl}$, critical intrusion.

may increase confabulation and false recognition (DelbecqDerouesné et al., 1990; Umeda and Kato, 2000; Umeda et al., 2001; Gilboa et al., 2006).

We tested whether the vmPFC plays a role in weighting the influence of schematic memory by evaluating false recall and recognition in patients with vmPFC lesions. We used the DRM paradigm, which promotes schematically consistent false memories (Roediger and McDermott, 1995). If vmPFC increases the weight of schematic memory, then damage to the vmPFC should change the relative influence of schematic and episodic knowledge by decreasing the influence of schematic memory and leading to fewer false memories. Thus, we predict that patients with vmPFC damage will have reduced false memory. Alternatively, normal performance would be expected if the vmPFC does not influence schematic memory.

\section{Materials and Methods}

Participants

Patients with vmPFC lesions ("vmPFC patients"; $n=7$; three males, four females; Table 1) were drawn from the Iowa Neurological Patient Registry, which contains data for patients with focal, stable brain lesions who underwent comprehensive neuropsychological testing at least 3 months after symptom onset. Lesions were verified using computerized tomography or magnetic resonance imaging and traced in a template space according to the MAP-3 lesion method (Damasio and Frank, 1992; Frank et al., 1997). Maximal overlap of the lesions was localized to the vmPFC (Fig. 1A). Healthy normal comparison participants (NC or "comparisons"; $n=14$; six males and eight females) matched to the vmPFC patients $(2: 1)$ on sex, age, and education were recruited from the Iowa City community. All participants granted informed consent and were paid; all procedures were conducted according to the Declaration of Helsinki. 
Table 2. Individual and group performance for recall and recognition tasks

\begin{tabular}{|c|c|c|c|c|c|c|c|}
\hline \multirow[b]{2}{*}{ Group/ID } & \multicolumn{2}{|l|}{ Recall (prop.) } & \multicolumn{3}{|c|}{ Recognition (SDT, prop.) } & \multicolumn{2}{|l|}{ Recognition $\left(d^{\prime}\right)$} \\
\hline & Studied items & Critical intrusions & Hit rate & FA rate & Crit. rate & Studied items & Critical items \\
\hline \multicolumn{8}{|l|}{ vmPFC } \\
\hline 0318 & 0.493 & 0.278 & 0.981 & 0.958 & 0.972 & 0.354 & 0.183 \\
\hline 2025 & 0.607 & 0.389 & 0.944 & 0.278 & 0.889 & 2.183 & 1.810 \\
\hline 2352 & 0.441 & 0.222 & 0.870 & 0.264 & 0.944 & 1.760 & 2.225 \\
\hline 2391 & 0.715 & 0.389 & 0.704 & 0.153 & 0.667 & 1.560 & 1.455 \\
\hline 3350 & 0.476 & 0.389 & 0.963 & 0.458 & 0.972 & 1.891 & 2.019 \\
\hline 3383 & 0.319 & 0.444 & 0.648 & 0.111 & 0.778 & 1.601 & 1.985 \\
\hline 3534 & 0.493 & 0.444 & 0.852 & 0.097 & 0.944 & 2.342 & 2.891 \\
\hline Mean \pm SEM & $0.506 \pm 0.047$ & $0.365 \pm 0.032$ & $0.852 \pm 0.049$ & $0.331 \pm 0.115$ & $0.881 \pm 0.044$ & $1.670 \pm 0.245$ & $1.795 \pm 0.316$ \\
\hline \multicolumn{8}{|l|}{ NC (group only) } \\
\hline $\begin{array}{l}\text { Mean } \pm \text { SEM } \\
\text { Group } \Delta\end{array}$ & $0.485 \pm 0.021$ & $0.524 \pm 0.043$ & $0.863 \pm 0.025$ & $0.233 \pm 0.038$ & $0.933 \pm 0.017$ & $2.021 \pm 0.117$ & $2.430 \pm 0.130$ \\
\hline Difference & -0.021 & 0.159 & 0.011 & -0.098 & 0.052 & 0.351 & 0.635 \\
\hline $95 \% \mathrm{Cl}$ & $(-0.113,0.071)$ & $(0.022,0.296)$ & $(-0.093,0.115)$ & $(-0.298,0.102)$ & $(-0.029,0.132)$ & $(-0.147,0.849)$ & $(0.035,1.234)$ \\
\hline$d_{\text {unb }}$ & 0.214 & 1.077 & 0.099 & 0.456 & 0.595 & 0.656 & 0.985 \\
\hline
\end{tabular}

Individual performance of all participating vmPFC patients is presented for proportion (prop.) recall of studied items and critical items (Crit.), for three categories of signal detection theory (SDT) responses, and for corrected recognition ( $d^{\prime}$ ) of studied and critical items. Group means for each measure are presented below, as are group mean differences, $95 \%$ (Is for the mean differences, and a standardized effect size measure with a correction for small sample sizes $\left(d_{\text {unb }}\right)$. Patient 0318 was unusual in that he showed recall performance that was typical of other vmPFC patients while also showing an extremely high false-alarm (FA) rate (bold) that markedly reduced his corrected true and false recognition performance (italicized). Statistics in this table include the performance of patient 0318. For statistics excluding his data, see Results. ID, Patient identification number.

\section{Materials}

False recall and recognition were evaluated using the DRM paradigm (Roediger and McDermott, 1995), which tests memory for word lists related to a nonpresented semantic associate, the critical item. By establishing a schema consistent with the critical item, the word lists promote false memory: during recall, critical items often intrude, and during recognition, critical items are often recognized. We selected 18 DRM word lists of 15 words each from published norms (Stadler et al., 1999). All words were pre-recorded by a female speaker. For the recognition task, 54 studied words were selected (items 1, 8, and 10 from each list), along with the 18 critical words. New items were 54 nonstudied words from other DRM word lists.

\section{Procedure}

Recall. Participants were instructed to listen to and remember prerecorded word lists played by a computer. Words were presented aurally at a rate of one every $2.5 \mathrm{~s}$. Immediately after the final word, participants were cued (visually) to begin recalling as many words as possible starting with the last list items to control for any group differences in recall order (Stuss et al., 1994) that might influence serial position effects. Participants recalled words until they indicated that they were finished, at which point the experimenter asked if they could recall any additional words. Afterward, the next list was presented. Participants practiced with one unique list before the main phase. After the final list was recalled, participants took a 3 min rest break.

Recognition. Words were presented to participants visually one at a time. Participants responded "yes" or "no" with a key press to indicate whether each item had been presented by the computer in the recall phase and then rated their confidence (1-4, low to high).

\section{Analysis}

Scoring recall performance. Recall performance was scored manually during the session by the experimenter (D.E.W. or S.H.J.). For seven comparisons and all vmPFC patients, scoring was confirmed by two raters who were blind to the experimental hypothesis using audio-video recordings. Blind-rater data were used in all analyses when available because it allowed measurement of order of recall and noncritical intrusions. For one vmPFC patient, several recordings were unavailable (4 of 18 lists for patient 3350); session-time scoring was used for those sessions.

Statistics. Statistical analysis was performed using R software (3.0.1). Group mean differences were calculated along with $95 \%$ confidence intervals (CIs). Repeated-measures ANOVA tests were used to evaluate fixed effects of group and true versus false memory for recall and recognition. Additionally, planned comparisons were conducted using nonpaired equal-variance $t$ tests to test group differences. Permutation tests of the planned comparisons are reported as $p_{\text {perm }}$ and were calculated as follows: bootstrapped distributions were created by assigning group membership to the data in $10^{5}$ randomly selected permutations, recording the statistic value for each permutation, and determining the percentile rank of the observed statistic value in the bootstrapped distribution. Effect size was measured with an unbiased variant of Cohen's $d$ that accounts for small sample sizes $\left(d_{\text {unb }}\right)$ (Grissom and Kim, 2012, p 70). Paired equal-variance $t$ tests, permutation tests, and Pearson's $r$ were used to evaluate the relationship between true recall and Rey Auditory Verbal Learning Test (AVLT) performance for patients; correlations between rates of false recall and other neuropsychological test scores were also evaluated. Between-group serial position effects were evaluated using a repeated-measures ANOVA implemented as a hierarchical linear model with participants as a random effect and post hoc linear contrasts at each serial position, corrected for multiple comparisons.

Recall. Studied-item recall was summarized as mean proportion recall across all lists: $\left(\sum_{i=1}^{L}\right.$ Items Recalled $_{i} /$ Items Presented $\left._{i}\right) / L$, where $L$ is the number of lists. Critical-item recall performance was summarized as the proportion of critical intrusions across all lists: Critical Intrusions/ $L$.

Corrected recognition. Recognition performance was characterized using $d^{\prime}$ (Macmillan and Creelman, 2005). Corrected true recognition used the studied-item hit rate, corrected false recognition used the criticalitem endorsement rate, and the false-alarm rate for new items was the same for both. Rates of 0 or 1 were replaced with values of $1 /(2 \times N)$ and $1-[1 /(2 \times N)]$, respectively, before calculation, with $N$ equal to the number of trials contributing to the analysis (Macmillan and Creelman, 2005).

\section{Results \\ Recall}

True recall performance was similar between the vmPFC and comparison groups, but the vmPFC group showed reduced false recall. Statistically, there was no main effect of group $\left(F_{(1,19)}=\right.$ $2.275, p=0.148)$ or accuracy of recall $\left(F_{(1,19)}=0.486, p=0.494\right)$, but the interaction of these factors was significant $\left(F_{(1,19)}=\right.$ $8.035, p=0.011)$. In planned comparisons, true recall was indistinguishable between the comparison and vmPFC groups $\left(t_{(19)}=\right.$ $0.482, p=0.635, p_{\text {perm }}=0.684$; Fig. $1 B$, left; Table 2$)$ and across serial positions $\left(F_{(14,265)}=1.305, p=0.204\right.$; Fig. $\left.1 D\right)$. Furthermore, vmPFC patients' true recall was positively (although marginally) correlated with previously measured word list recall [AVLT trial 1; Pearson's $r=0.687, p=0.088,95 \% \mathrm{CI}=(-0.138$, $0.949)]$. In support of our prediction, vmPFC patients reported significantly fewer critical items than comparisons $\left(t_{(19)}=2.424\right.$, 
$p=0.025, p_{\text {perm }}=0.006 ;$ Fig. $1 B$, right; Table 2$)$. This pattern was exemplified by one vmPFC patient (2391) who had the best true recall performance observed in either group (proportion recall, $0.715)$ but whose critical intrusion rate $(0.389)$ was well below the normal mean of 0.524 . Also, there was a global reduction in critical intrusion rates for all 18 lists ranked on effectiveness for each group (Fig. 1E), a highly unlikely outcome if list effectiveness was similar across groups (binomial test, $p<0.001$ ). Meanwhile, similar numbers of noncritical intrusions were made by both groups (NC mean \pm SEM, $0.405 \pm 0.125$; vmPFC mean, $0.468 \pm$ $\left.0.074 ; t_{(12)}=0.439, p=0.669, p_{\text {perm }}=0.636, d_{\text {unb }}=0.219\right)$.

\section{Recognition}

True recognition was similar for the vmPFC and comparison groups, but there was some evidence indicating reduced false recognition in the vmPFC group. The comparison and vmPFC groups correctly endorsed most studied items (hit rates, not statistically different, $t_{(19)}=0.223, p=0.826, p_{\text {perm }}=0.398$ ), correctly rejected most nonstudied items (false-alarm rates, not statistically different, $\left.t_{(19)}=1.027, p=0.317, p_{\text {perm }}=0.817\right)$, and incorrectly endorsed most critical items (critical endorsement rates; not statistically different, $t_{(19)}=1.338, p=0.197, p_{\text {perm }}=$ 0.095 ) with very high confidence [NC mean \pm SEM: old, $3.763 \pm$ 0.050; critical, $3.795 \pm 0.079$; vmPFC mean \pm SEM: old, $3.572 \pm$ 0.090; critical, $3.610 \pm 0.202)$. Corrected recognition scores $\left(d^{\prime}\right)$ showed that false recognition was greater than true recognition overall $\left(F_{(1,19)}=13.830, p=0.001\right)$. The effect of group was marginal $\left(F_{(1,19)}=3.966, p=0.061\right)$, and there was limited evidence of an interaction between factors $\left(F_{(1,19)}=2.496, p=\right.$ 0.131). Despite this, planned comparisons showed that the vmPFC group had reduced corrected false recognition $\left(t_{(19)}=\right.$ $2.216, p=0.039, p_{\text {perm }}=0.023$; Fig. $\left.1 C\right)$. Corrected true recognition differed no more than marginally between groups $\left(t_{(19)}=\right.$ $\left.1.477, p=0.156, p_{\text {perm }}=0.087\right)$. This analysis was repeated while excluding the data of one vmPFC patient with an unusually high false-alarm rate (Table 2), and the effect size of the group difference in false recognition remained large $\left(d_{\text {unb }}=0.722\right)$ but was statistically marginal $\left(t_{(18)}=1.545, p=0.140, p_{\text {perm }}=0.069\right)$.

\section{Supporting analyses}

We conducted several additional analyses to investigate the specificity of the reduced false recall of the vmPFC group. For example, false recall could be reduced by defective semantic memory or impaired ability to generate words in response to cues. The patients did not have any notable learning impairment on several neuropsychological tests of memory, and their normal verbal IQ scores suggested intact semantic memory (note that verbal IQ subtests including Similarities, Information, and Vocabulary tax semantic memory; Table 1). Patients performed the Controlled Oral Word Association (COWA) test and a category fluency test normally on average, suggesting intact generation abilities. Additionally, there were no significant correlations between false recall and COWA $\left(r=-0.434, t_{(5)}=1.076, p=0.331\right)$ or category fluency $\left(r=-0.048, t_{(5)}=0.107, p=0.919\right)$ performance. These results show that vmPFC damage produced a specific reduction in false recall rather than a generalized deficit.

There is some evidence (Deese, 1959) that schematic memory may improve recall of schematically consistent lists (e.g., DRM word lists) versus schematically inconsistent lists (e.g., AVLT word lists). If vmPFC damage alters schematic memory processes, beneficial schema-related effects should be reduced alongside negative effects. To the extent that this prediction would be true, then schematic consistency among DRM list items could have enhanced true recall for comparisons but not for vmPFC patients. Our design did not address this corollary prediction directly, but associative strength between items on a DRM list and the critical item is not correlated with true recall (Roediger et al., 2001). Consistent with this, we did not observe a group difference in true recall, nor did we find significant evidence for a schematic benefit to true recall in either group. Comparison participants did not complete the AVLT, but normative proportion recall expectations on AVLT trial 1 (Schmidt, 1996) were reported as mean of $0.393,95 \% \mathrm{CI}=(0.180,0.607)$, which encompasses the true recall performance of both groups (NC, 0.485 ; vmPFC, 0.506). Furthermore, contrasting the true recall of the vmPFC group with their AVLT trial 1 recall revealed no statistical difference (AVLT trial 1 mean, $0.505 \pm 0.060$; DRM mean, $0.506 \pm$ $\left.0.047 ; t_{(6)}=0.031, p=0.976, p_{\mathrm{perm}}=0.510, d_{\mathrm{unb}}=0.009\right)$. These supplemental analyses do not support the proposition that recall performance of either group benefitted from schematic consistency among word lists. Future investigations could evaluate effects of vmPFC damage on schematic enhancement of memory directly. Based on previous research (Deese, 1959) and our findings, we predict that sensitive measurement could show a small but significant reduction in true recall complementing the reduction in false recall we observed.

\section{Discussion}

We found that patients with vmPFC damage showed significantly reduced false recall of schematically consistent words and some evidence that false recognition was also reduced. These findings have important implications for the cognitive neuroscience of memory because they unite converging results from studies using animal models (Euston and McNaughton, 2006; Tse et al., 2007, 2011 ) and functional neuroimaging of healthy participants (Kumaran et al., 2009; van Kesteren et al., 2010, 2013; Bonnici et al., 2012; Zeithamova et al., 2012a,b) that suggested a key role for vmPFC in integrating information into schematic memory or weighting the influence of schematic memory. Notably, complementary or alternative explanations for the observed contributions of vmPFC to false memory are also plausible, including schema generation or maintenance.

Schema acquisition is often operationalized as integrating conceptual knowledge about a novel task, a process that selectively engages hippocampus and vmPFC (Kumaran et al., 2009; Zeithamova et al., 2012b). Schemas should also support rapid new learning (Bransford and Johnson, 1972), and this ability has been directly tied to the rodent prelimbic region (a vmPFC homolog) (Tse et al., 2007, 2011). Evidence for a similar relationship in humans was found in neuroimaging data (van Kesteren et al., 2010): participants studied information presented in a schematically consistent or inconsistent manner, and, for the schemastudy group, delayed test performance was associated with increased functional connectivity between vmPFC and hippocampus. This result converges with other work to indicate that vmPFC is strongly related to the acquisition and use of schematic information.

Our demonstration that vmPFC is important for normal false memory processes complements the acknowledged importance of the vmPFC as a convergence zone for environmental, physiological, and mnemonic signals arising from posterior cortical regions that can influence response selection in complex decisions (Damasio, 1994; Bechara et al., 1997; Bechara and Damasio, 2005). From a lifespan development perspective, age-related changes to the neuroanatomy of PFC (Raz et al., 2005) or larger memory-related networks (Andrews-Hanna et al., 2007) may increase susceptibility to false memory phenomena, such as false 
recall (Norman and Schacter, 1997; Schacter et al., 1997; Butler et al., 2004) that could manifest in real-world vulnerabilities (e.g., to deceptive advertising; Denburg et al., 2007). In the context of healthy aging, our findings resemble those of a previous investigation contrasting DRM recall of young and older adults (Norman and Schacter, 1997). Older adults in both studies (including vmPFC patients) showed similar true recall and false recall of healthy older participants was also similar. Intriguingly, false recall by young adults was less frequent and closely resembled that of our vmPFC group, suggesting that vmPFC damage may offset age-related increases in false recall. We speculate that vulnerability to false recall in older adults could be attributable to overreliance on schematic memory because of age-related impairment of episodic memory functions (Balota et al., 2000) associated with reductions in hippocampal volume (Allen et al., 2005; Raz et al., 2005), and future research could address that relationship.

We found some evidence that vmPFC damage reduces both false recall and false recognition, effects not reported previously to our knowledge. The smaller effect size of between-group differences in false recognition could potentially have been attributable to a ceiling effect. Our design included auditory study followed by visual recognition test and produced high false recognition rates in both groups (Table 2), but future studies could potentially adapt our methodology to reduce false recognition for all groups (Gallo et al., 2001). Our findings differ from previous reports of DRM recognition by vmPFC patients which found that patients endorsed studied, unstudied, and critical items more frequently than comparisons (Umeda and Kato, 2000; Umeda et al., 2001). Nonspecific high rates of endorsement would suggest a general relaxation of recognition memory criteria that we observed in only one patient (Table 2), whereas the rest of the vmPFC group had normal true recognition. Furthermore, patients in our study did not produce more studied or nonstudied items during recall (cf. Delbecq-Derouesné et al., 1990), again suggesting normal response criteria. Differences with previous reports may be attributable to neuroanatomical, neuropsychological, demographic, or task variables. We believe that our vmPFC sample is unusually intact neuropsychologically (Table 1) and has a relatively focal and homogeneous distribution of lesions (Fig. 1A).

Memory distortions are a pervasive phenomenon observed across healthy populations (Roediger and McDermott, 1995), patients with severe amnesia (Schacter et al., 1996), and even people with highly superior autobiographical memory (Patihis et al., 2013). The latter authors remarked that, "Although it is always possible that some group might be found to be immune to memory distortions, none has as yet been discovered." While vmPFC patients were not strictly "immune," the pronounced reduction in the false recall of vmPFC patients suggests that the vmPFC plays an important role in false memory processes and in the weighting of schematic memories beyond its acknowledged role in decision making. Our findings provide novel insight into the role of the vmPFC in schematic memory, link the literatures of decision making and memory, and suggest that the vmPFC participates in a memory network that includes the MTL and hippocampus.

\section{References}

Alba J, Hasher L (1983) Is memory schematic? Psychol Bull 93:203-231. CrossRef

Allen JS, Bruss J, Brown CK, Damasio H (2005) Normal neuroanatomical variation due to age: the major lobes and a parcellation of the temporal region. Neurobiol Aging 26:1245-1260, discussion 1279-1282. Medline

Andrews-Hanna JR, Snyder AZ, Vincent JL, Lustig C, Head D, Raichle ME,
Buckner RL (2007) Disruption of large-scale brain systems in advanced aging. Neuron 56:924-935. CrossRef Medline

Andrews-Hanna JR, Reidler JS, Sepulcre J, Poulin R, Buckner RL (2010) Functional-anatomic fractionation of the brain's default network. Neuron 65:550-562. CrossRef Medline

Balota DA, Dolan PO, Ducheck JM (2000) Memory changes in healthy older adults. In: The Oxford handbook of memory, pp 395-409. New York: Oxford UP.

Bartlett F (1932) Remembering. Cambridge, UK: Cambridge UP.

Bechara A, Damasio AR (2005) The somatic marker hypothesis: a neural theory of economic decision. Games Econ Behav 52:336-372. CrossRef

Bechara A, Damasio H, Tranel D, Damasio AR (1997) Deciding advantageously before knowing the advantageous strategy. Science 275:12931295. CrossRef Medline

Bonnici HM, Chadwick MJ, Lutti A, Hassabis D, Weiskopf N, Maguire EA (2012) Detecting representations of recent and remote autobiographical memories in vmPFC and hippocampus. J Neurosci 32:16982-16991. CrossRef Medline

Bransford JD, Johnson MK (1972) Contextual prerequisites for understanding: some investigations of comprehension and recall. J Verbal Learn Verbal Behav 11:717-726. CrossRef

Butler KM, McDaniel MA, Dornburg CC, Price AL, Roediger HL 3rd (2004) Age differences in veridical and false recall are not inevitable: the role of frontal lobe function. Psychon Bull Rev 11:921-925. CrossRef Medline

Cohen NJ, Squire LR (1980) Preserved learning and retention of patternanalyzing skill in amnesia: dissociation of knowing how and knowing that. Science 210:207-210. CrossRef Medline

Damasio AR (1994) Descartes' error: emotion, reason, and the human brain. New York: Putnam.

Damasio H, Frank R (1992) Three-dimensional in vivo mapping of brain lesions in humans. Arch Neurol 49:137-143. CrossRef Medline

Deese J (1959) Influence of inter-item associative strength upon immediate free recall. Psychol Rep 5:305-312. CrossRef

Delbecq-Derouesné J, Beauvois MF, Shallice T (1990) Preserved recall versus impaired recognition. A case study. Brain 113:1045-1074. CrossRef Medline

Denburg NL, Cole CA, Hernandez M, Yamada TH, Tranel D, Bechara A, Wallace RB (2007) The orbitofrontal cortex, real-world decision making, and normal aging. Ann N Y Acad Sci 1121:480-498. CrossRef Medline

Euston DR, McNaughton BL (2006) Apparent encoding of sequential context in rat medial prefrontal cortex is accounted for by behavioral variability. J Neurosci 26:13143-13155. CrossRef Medline

Frank RJ, Damasio H, Grabowski TJ (1997) Brainvox: an interactive, multimodal visualization and analysis system for neuroanatomical imaging. Neuroimage 5:13-30. CrossRef Medline

Gallo DA, McDermott KB, Percer JM, Roediger HL 3rd (2001) Modality effects in false recall and false recognition. J Exp Psychol Learn Mem Cogn 27:339-353. CrossRef Medline

Gilboa A, Alain C, Stuss DT, Melo B, Miller S, Moscovitch M (2006) Mechanisms of spontaneous confabulations: a strategic retrieval account. Brain 129:1399-1414. CrossRef Medline

Grissom RJ, Kim JJ (2012) Effect sizes for research: univariate and multivariate applications. New York: Routledge.

Janowsky JS, Shimamura AP, Kritchevsky M, Squire LR (1989) Cognitive impairment following frontal lobe damage and its relevance to human amnesia. Behav Neurosci 103:548-560. CrossRef Medline

Koenigs M, Young L, Adolphs R, Tranel D, Cushman F, Hauser M, Damasio A (2007) Damage to the prefrontal cortex increases utilitarian moral judgements. Nature 446:908-911. CrossRef Medline

Kumaran D, Summerfield JJ, Hassabis D, Maguire EA (2009) Tracking the emergence of conceptual knowledge during human decision making. Neuron 63:889-901. CrossRef Medline

Lezak MD, Howieson DB, Bigler ED, Tranel D (2012) Neuropsychological assessment. New York: Oxford UP.

Macmillan NA, Creelman CD (2005) Detection theory: a user's guide. Mahwah, NJ: Erlbaum.

Norman KA, Schacter DL (1997) False recognition in younger and older adults: exploring the characteristics of illusory memories. Mem Cognit 25:838-848. CrossRef Medline

Ongür D, Price JL (2000) The organization of networks within the orbital 
and medial prefrontal cortex of rats, monkeys and humans. Cereb Cortex 10:206-219. CrossRef Medline

Patihis L, Frenda SJ, LePort AK, Petersen N, Nichols RM, Stark CE, McGaugh JL, Loftus EF (2013) False memories in highly superior autobiographical memory individuals. Proc Natl Acad Sci US A 110:20947-20952. Medline

Ranganath C, Heller A, Cohen MX, Brozinsky CJ, Rissman J (2005) Functional connectivity with the hippocampus during successful memory formation. Hippocampus 15:997-1005. CrossRef Medline

Raz N, Lindenberger U, Rodrigue KM, Kennedy KM, Head D, Williamson A, Dahle C, Gerstorf D, Acker JD (2005) Regional brain changes in aging healthy adults: general trends, individual differences and modifiers. Cereb Cortex 15:1676-1689. CrossRef Medline

Roediger HL 3rd, McDermott KB (1995) Creating false memories: remembering words not presented in lists. J Exp Psychol Learn Mem Cogn 21: 803-814. CrossRef

Roediger HL 3rd, Watson JM, McDermott KB, Gallo DA (2001) Factors that determine false recall: a multiple regression analysis. Psychon Bull Rev 8:385-407. CrossRef Medline

Saleem KS, Kondo H, Price JL (2008) Complementary circuits connecting the orbital and medial prefrontal networks with the temporal, insular, and opercular cortex in the macaque monkey. J Comp Neurol 506:659-693. CrossRef Medline

Schacter DL, Verfaellie M, Pradere D (1996) The neuropsychology of memory illusions: false recall and recognition in amnesic patients. J Mem Lang 35:319-334. CrossRef

Schacter DL, Koutstaal W, Johnson MK, Gross MS, Angell KE (1997) False recollection induced by photographs: a comparison of older and younger adults. Psychol Aging 12:203-215. CrossRef Medline

Schmidt M (1996) Rey auditory verbal learning test: a handbook. Los Angeles: Western Psychological Services.

Scoville WB, Milner B (1957) Loss of recent memory after bilateral hippocampal lesions. J Neurol Neurosurg Psychiatr 20:11-21. CrossRef Medline
Stadler MA, Roediger HL 3rd, McDermott KB (1999) Norms for word lists that create false memories. Mem Cognit 27:494-500. CrossRef Medline

Stuss DT, Alexander MP, Palumbo CL, Buckle L, Sayer L, Pogue J (1994) Organizational strategies with unilateral or bilateral frontal lobe injury in word learning tasks. Neuropsychology 8:355-373. CrossRef

Tse D, Langston RF, Kakeyama M, Bethus I, Spooner PA, Wood ER, Witter MP, Morris RGM (2007) Schemas and memory consolidation. Science 316:76-82. CrossRef Medline

Tse D, Takeuchi T, Kakeyama M, Kajii Y, Okuno H, Tohyama C, Bito H, Morris RGM (2011) Schema-dependent gene activation and memory encoding in neocortex. Science 333:891-895. CrossRef Medline

Umeda S, Kato M (2000) Receiving emotional signals and retrieving past similar events: higher-order cognitive dysfunction following damage to the ventromedial prefrontal cortex. In: Affective minds (Hatano G, Okada N, Tanabe H, eds), pp 111-115. Amsterdam: Elsevier Science.

Umeda S, Akine Y, Kato M (2001) False recognition in patients with ventromedial prefrontal lesions. Brain Cognit 47:362-365.

van Kesteren MTR, Fernández G, Norris DG, Hermans EJ (2010) Persistent schema-dependent hippocampal-neocortical connectivity during memory encoding and postencoding rest in humans. Proc Natl Acad Sci U S A 107:7550-7555. CrossRef Medline

van Kesteren MTR, Ruiter DJ, Fernández G, Henson RN (2012) How schema and novelty augment memory formation. Trends Neurosci 35 : 211-219. CrossRef Medline

van Kesteren MT, Beul SF, Takashima A, Henson RN, Ruiter DJ, Fernández G (2013) Differential roles for medial prefrontal and medial temporal cortices in schema-dependent encoding: from congruent to incongruent. Neuropsychologia 51:2352-2359. CrossRef Medline

Zeithamova D, Schlichting ML, Preston AR (2012a) The hippocampus and inferential reasoning: building memories to navigate future decisions. Front Hum Neurosci 6:70. Medline

Zeithamova D, Dominick AL, Preston AR (2012b) Hippocampal and ventral medial prefrontal activation during retrieval-mediated learning supports novel inference. Neuron 75:168-179. CrossRef Medline 